\title{
CFD Analysis of Hybrid Solar Chimney Power Plant
}

\author{
Mohammed A. Aurybi ${ }^{1,2}$, Hussain H. Al-Kayiem ${ }^{1,}{ }^{*}$, Syed I. U. Gilani ${ }^{1}$ and Ali A. Ismaee ${ }^{1}$ \\ ${ }^{1}$ Solar Thermal Advanced Research Center [STARC], Universiti Teknologi PETRONAS, 32610 \\ Bandar Seri Iskandar, Perak, Malaysia. \\ ${ }^{2}$ Department of Mechanical Engineering, University of Baghdad, Baghdad, Iraq
}

\begin{abstract}
In this study, a novel approach has been proposed as a solar chimney integrated with an external heat source to extend the system operation during the absence of solar energy. Flue gas channels have been utilized to exchange heat with the air inside the collector of the solar chimney. The hybrid solar chimney has been investigated numerically by ANSYS-Fluent software, using discrete ordinates radiation model. The hybrid system was simulated in 3D, steady-state by solving Navier-Stokes and energy equations. The numerical results have been validated using experimental measurements of a conventional solar chimney. The influence of flue channels on the system performance was predicted and analyzed in hybrid mode. With $0.002 \mathrm{~kg} / \mathrm{s}$ of flue gas at $100^{\circ} \mathrm{C}$ injected in flue channels during the daytime; hybrid mode results demonstrated enhancement of $24 \%$ and $9 \%$ for velocity and temperature, respectively. The power generation was enhanced by $56 \%$. It has been proved that the proposed technique is able to resolve the set back of night operation problem of the solar chimney plants.
\end{abstract}

\section{Introduction}

The increase in solar energy utilization promotes the developing of Solar Chimney Power Plant (SCPP) technology. SCPP is a thermal conversion unit to generate electricity using the solar energy as the primary energy source. This type of plants is uncomplicated and contain key parts simple free of complexity. These parts are: collector (greenhouse), chimney and turbine. Physically solar radiation is transparent through the collector cover and received by the ground (absorber) and the air inside the collector. Some of the heat is storage by the ground and the rest goes to the air inside the collector. At cloudy days or at night the heat storage is released from the absorber to the air, but this heat storage cannot always meet the need of plant operation during the night or overcast weather. Low conversion efficiency and poor efficiency level represents one of the major problems of SCPP [1]. This problem can solve by increasing the collector area and chimney height, but that have some limitations especially the construction materials and some construction difficulties. To get rid of the plant low efficiency and the decline in power generation during the cloudy day or at night, many researchers suggested integration of the conventional SCPP with another system to construct a non-conventional SCPP.

* Corresponding author: hussain kayiem@utp.edu.my 
Other researchers suggested integration of the SCPP with external source to enhance the performance and to survive the system from power decline at night. A hybrid SCPP to enhance the power production at day and cloudy period operation is proposed by [2] by combined Geothermal/PV/SCPP. [3] suggested a combined system by using the chimney top of the SCPP as a tower of the solar receiver to generate steam by heliostat and the SCPP work as its principles. [4] proposed a new power plant plan by using the SCPP with solid oxide fuel cells. [5-7] combining solar chimney with a natural draft dry cooling tower to enhance SCPP electricity generation and at the same time exploit the waste heat.

On the other side, there are many applied technologies which use and transform the waste energy to useful form. There is a significant percentage increase in a global market of waste to energy and expected to continue with steady growth [8]. [9-11] proposed a hybrid SCPP by installing thermal enhancing channels underneath the collector canopy, mathematically. The proposed channels can be work as a heat exchanger. [12] and [13] proposed hybrid SCPP model to enhance the plant performance by utilizing metal sheet as the absorber plate underneath the collector instead of the soil, the absorber plate stands as a heat exchanger which extract heat from the hot flue gas that flows through the bottom part of the collector while in the top/front of the absorber plate there was a collector which absorbed the solar energy to warm up the air inside it. However, [14] have registered a patent on the integration of the solar chimney power plant with external heat source. [15] proposed a hybrid system called "solar chimney-aided dry cooling system" which used the waste heat which released by condenser of coal-fired power plant to heat up the collector inlet air of solar chimney. [13] have carried out experimental work on utilization of flue gas, but the configuration of the collector is inclined rectangular absorber.

The problems attendant with the SCPP concluded from the literatures was the low efficiency, high thermal losses with fluctuation and variation in generated energy through the day, month and year and also the lack in solar radiation at night caused no electric generation. All previous enhancements for the plant cannot subsist to make it work 24 hours.

Considering the problems associated with the conventional SCPP, the main objective of this paper is to introduce a proposed model of Hybrid Solar Chimney (HSC). A model of conventional solar chimney (SC) is integrated with external source of heat, namely, flue gas. The investigations have been carried out experimentally and numerically. In addition to the base case of conventional SC, another two cases have been considered, without and with flue injection in the new HSC model.

\section{Description of the proposed model}

The proposed HSC utilized the flue gas waste heat which can be generated from the industrial operations or any external heat source and integrated with the conventional solar system to enhance the performance of the plant. The proposed system employs and uses flue gas as the only source of its night operation. HSC system is shown schematically in Fig. 1. In the proposed HSC, the wasted thermal energy in the exhaust gasses could be recovered as useful energy to heat up the air in the collector of the proposed system.

The gases are directed to flow inside four channels, situated below the collector cover. Air will gain more thermal energy in addition to that obtained from the absorber. Air temperature at the collector outlet will be increased, resulting in enhancing the HSC performance.

This arrangement will continue supply heat to the air inside the collector and secure the plant to operate even at night. Flue gas entry to the channels is done by a set of pipes while the flue gases which exit from the channels are connected to the pipes where its numbers depending on the flue channels numbers. For more energy recovery, another consideration is 
proposed by injection the exit flue gas into the air chimney which called "co-generation technique".

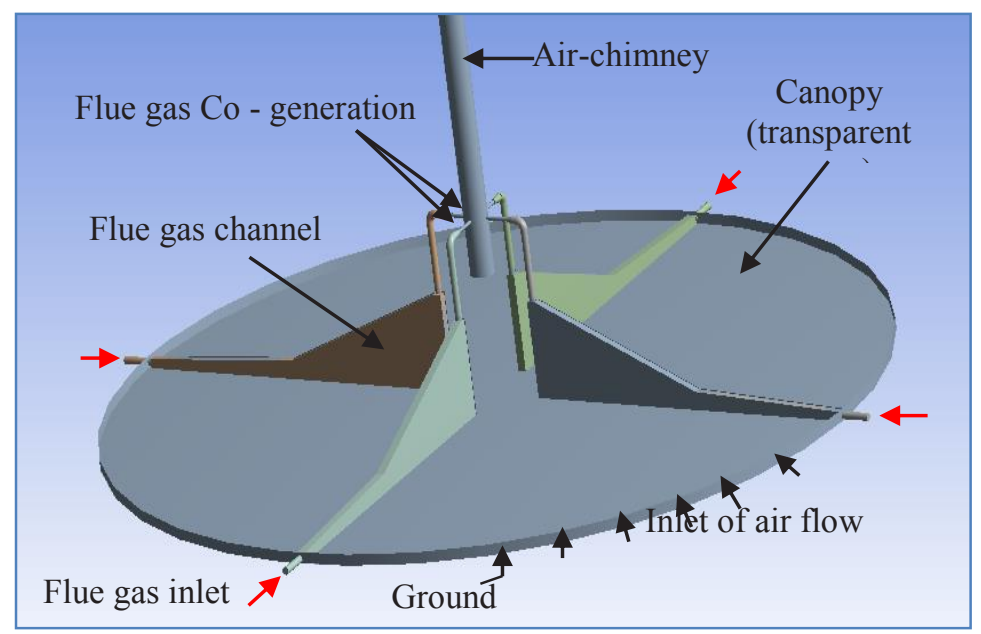

Fig. 1. Schematic diagram of proposed model

\section{Numerical procedures}

\subsection{Computational model and governing equations.}

The proposed HSC model, shown in Fig. 2 was tested after adding the flue channels with flue gas, at day and night mode. The input parameters which added to the model were the flue gas velocity and temperature inlet values to the flue channels. The main input parameter in simulation was the solar irradiation, $I$ which is assumed $\left(100-1000 \mathrm{~W} / \mathrm{m}^{2}\right)$ in steps 100 and the ambient temperature $\left(30-34^{\circ} \mathrm{C}\right)$. In the numerical model, the ground material was assumed painted black pebble with thickness of $0.1 \mathrm{~m}$ to increase the heat storage as recommended by [16] and underneath the pebble, the soil was considered $0.3 \mathrm{~m}$ thickness.

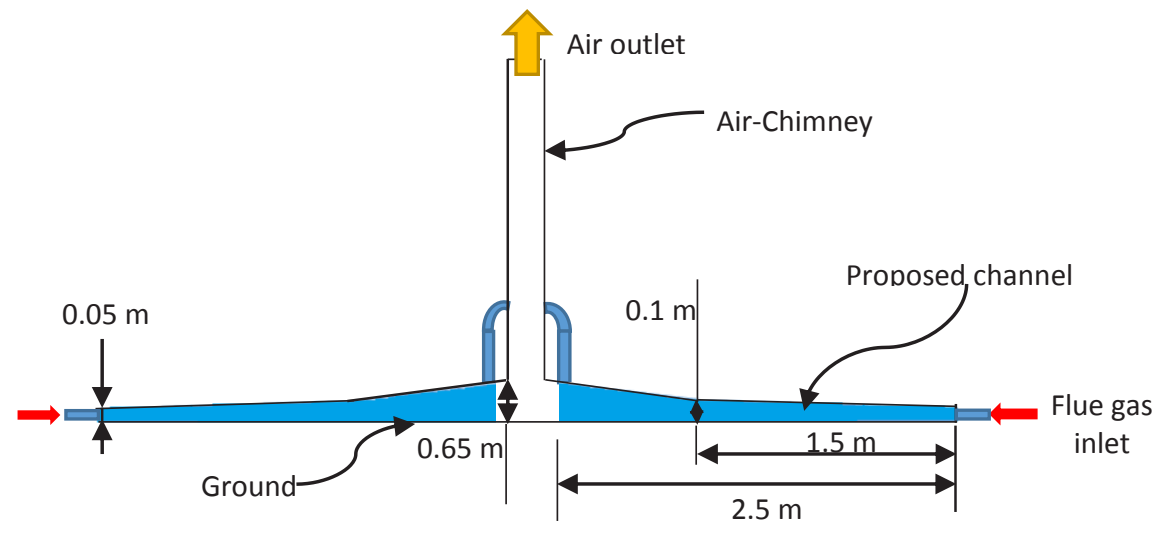

Fig. 2. Schematic diagram of the proposed HSC model with co-gen

The conservation equations of mass, momentum and energy have been solved iteratively in ANSYS FLUENT environment under 3D, steady, assumptions for fluid flow were The source terms in the momentum equation are representing the body forces in $\mathrm{x}, \mathrm{y}, \mathrm{z}$ directions. 
As incompressible with constant viscosity, body force is acting in y-direction only. The gravitational acceleration is $0,-\mathrm{g}, 0$ in $\mathrm{x}, \mathrm{y}, \mathrm{z}$, respectively. However, Boussinesq model was used in numerical solution which treats density in solved equations as a constant value in all solved equations; except for the buoyancy term in the momentum equation govern the upward flow direction.

\subsection{Mesh generation}

The conventional and proposed computational models have been achieved by GAMBIT and then exported to ANSYS FLUENT 15. Mesh generation and grid independency was accomplished. The structured mesh tetrahedral type was used to achieve the mesh generation for conventional SCPP model and mesh sizing (Maximum size $0.03 \mathrm{~m}$ and minimum size $0.001 \mathrm{~m}$ ) and unstructured mesh type were used to get the solution for the hybrid proposed model.

\subsection{Boundary conditions}

The boundary conditions are presented in Table 1 . The material physical properties for the air inside the geometry and for the solid parts were employed in the simulation.

Table 1. Boundary conditions for conventional and proposed model

\begin{tabular}{|l|c|c|}
\hline \multicolumn{1}{|c|}{ Zone } & Type & Value \\
\hline Ground & Interface wall & Interface \\
\hline Canopy & Semi-transparent wall & $h=7 \mathrm{w} / \mathrm{m}^{2}, T_{a m b}=307 \mathrm{~K}$ \\
\hline Chimney & wall & Adiabatic \\
\hline Collector inlet & Pressure inlet & $\mathrm{P}_{\text {gage }}=0, T_{\text {amb }}=307 \mathrm{~K}$ \\
\hline Chimney outlet & Pressure outlet & $\mathrm{P}_{\text {gage }}=0, T_{\text {amb }}=307 \mathrm{~K}$ \\
\hline Flue gas inlet-each channels & Velocity and temperature & vgas in $=2 \mathrm{~m} / \mathrm{s}, T_{\text {gas } i n}=373 \mathrm{~K}$ \\
\hline
\end{tabular}

\section{Results and discussion}

Experimental conventional SC model was implemented in the Solar Thermal Advanced Research Center (STARC) at Universiti Teknologi PETRONAS (UTP) - Malaysia (latitude $\left.4.387^{\circ} \mathrm{N}, 100.97^{\circ} \mathrm{E}\right)$. Comparison of the numerical solution results against experimental measurement results were carried out. Once the numerical procedure was validated, then the hybrid model was tested numerically by simulation after adding flue channels with flue gas injection at hybrid (solar + external heat source) and night mode (only external heat source). The temperature difference and velocity at the chimney base in simulation for the conventional model were in good agreement with the experimental readings depicting logical and reasonable error ratio $(8.7 \%$ for velocity and $7.8 \%$ for temperature).

\subsection{Simulation results for conventional model}

Velocity and temperature contour maps were considered as benchmark case based on simulation results with no load condition. The sun position effect was considered in all numerical solution cases which gave more accurate solution and more accurate ground temperature prediction. The maximum velocity for the numerical solution of the convenience model was $1.97 \mathrm{~m} / \mathrm{s}$ and the temperature was $325 \mathrm{~K}\left(\Delta \mathrm{T}=18^{\circ} \mathrm{C}\right)$ as shown in Figure 3 (a) and (b) when the solar intensity was $1000 \mathrm{~W} / \mathrm{m}^{2}$. It could be observed that by simulation, the maximum velocity was observed at the base of the chimney and the temperature distributions 
increased when the solar insolation increased. The maximum velocity for the numerical solution of the convenience model was $1.82 \mathrm{~m} / \mathrm{s}$ and $1.76 \mathrm{~m} / \mathrm{s}$ for the experiment when the solar intensity was $905 \mathrm{~W} / \mathrm{m}^{2}$. At night, the experimental measured data recorded that the air velocity at the chimney base was $0.4-0.5 \mathrm{~m} / \mathrm{s}$ and showed that this velocity cannot rotate the turbine and generate electricity at night. The simulation results showed that the air velocity at the chimney base $0.6 \mathrm{~m} / \mathrm{s}$ when the solar intensity $0 \mathrm{~W} / \mathrm{m}^{2}$ and ambient temperature was $300 \mathrm{~K}$ at night mode.

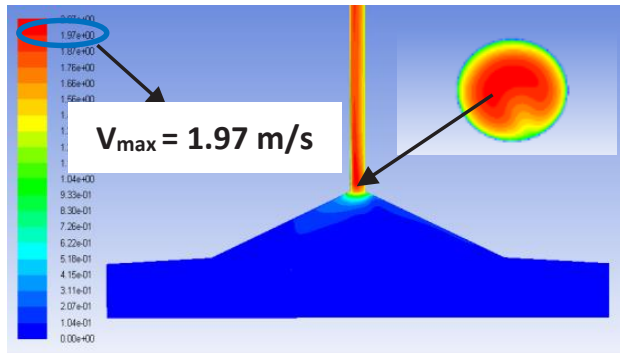

(a)

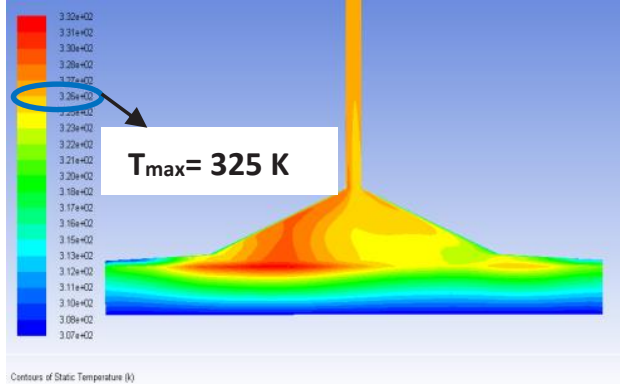

(b)

Fig. 3. Velocity (a) and temperature (b) contour for the conventional model

\subsection{Simulation results for hybrid model}

The numerical solution was achieved for the proposed model after push flue gas or external heat source flow inside the channels by assuming mass flow rate $0.002 \mathrm{~kg} / \mathrm{s}$ (velocity $2 \mathrm{~m} / \mathrm{s}$ ) and temperature $100{ }^{\circ} \mathrm{C}$ in each channel. Figure 4 shows the velocity and temperature of simulation results for air flow at the chimney base after push flue gas with $2 \mathrm{~m} / \mathrm{s}$ velocity and $100{ }^{\circ} \mathrm{C}$ temperature and considering the co-generation technique.

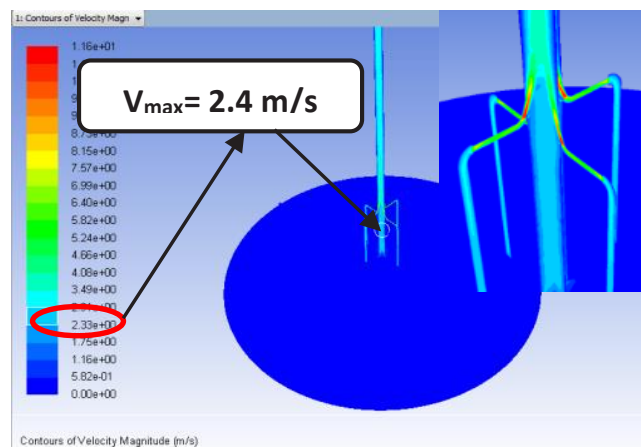

(a)

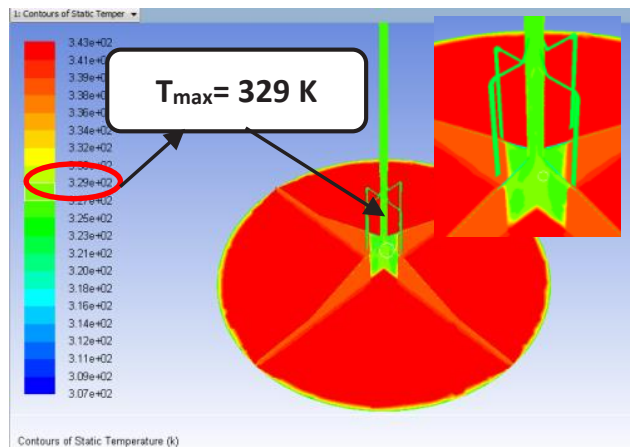

(b)

Fig. 4. Velocity (a) and temperature; (b) contour for the proposed model with co-gen technique

The increased velocity of the air at the chimney base was from the air temperature increasing which absorbed more heat from the proposed flue channels and from the geometry (channels installation) due to collector cross-section area reduction which enhance the air kinetic energy of working fluid at the chimney base. The co-gen of flue gas inside the chimney caused increasing the velocity at the chimney base. The maximum air velocity at the chimney base reached to $2.4 \mathrm{~m} / \mathrm{s}$ compared with $1.82 \mathrm{~m} / \mathrm{s}$ for conventional model. 


\section{Conclusion}

Hybrid solar chimney technique has been proposed and analyzed in the present work. The simulation of the conventional model showed a good agreement with the experimental results which carried out in Solar Thermal Advanced Research Center (STARC). The numerical results disclose that the proposed hybrid solar chimney has a momentous impact on the system performance. The maximum generated power for conventional model was $0.65 \mathrm{~W}$ and for proposed model was $1.49 \mathrm{~W}$ which means that the proposed model can enhance the electric power generation by $56 \%$ at the maximum velocity and solar intensity values. At night, the calculated generated power for conventional model was $0.02 \mathrm{~W}$, and for the proposed model with co-gen technique was $0.27 \mathrm{~W}$ and enhancement $93 \%$, which proves that the proposed model can continue to generate electricity during the night and 24 hours.

The logistic and technical supports provided by Universiti Teknologi PETRONAS under grant SoTL 0152AA-A72 is greatly acknowledged. The main author, in particular, acknowledges Ministry of Industry and Minerals - Iraq (SIER-Company) for assistance to pursue his PhD study. Ministry of Higher Education (MOHE) - Malaysia is acknowledged for supporting the experimental work of the project under FRGS/1/2017/STG02/UTP/01/1, CS: 0153AB-L58.

\section{References}

1. J. Schlaich, R. Bergermann, W. Schiel, and G. Weinrebe, Structural Engineering International 14, 225-229 (2004).

2. H. Alrobaei, Higher Institute of Engineering, HOON; LIBYA (2007).

3. Z. R. Yabuz," MSc thesis, SDÜ Fen Bilimleri Enstitüsü, 2009.

4. O. J. Shariatzadeh, A. H. Refahi, S. S. Abolhassani, and M. Rahmani, Energy Conversion and Management 105, 423-432 (2015).

5. Z. Zou and S. He, Energy Conversion and Management 95, 59-68 (2015).

6. Z. Zou and H. Gong, Applied Thermal Engineering 94, 697-705 (2016).

7. A. Zandian and M. Ashjaee, Renewable Energy 51, 465-473 (2013).

8. World Energy Resources Report, 24th edition (2016).

9. M. A. Aurybi, H.H. Al-Kayiem, S.I.U. Gilani and A.A. Ismaeel, ARPN Journal of Engineering and Applied Sciences 11, NO. 20 (2016).

10. M. A. Aurybi, H.H. Al-Kayiem, S.I.U. Gilani and Ali A. Ismaeel, WIT Transactions on Ecology and the Environment 226, WIT Press (2017).

11. M. A. Aurybi, H.H. Al-Kayiem, S. I. U. Gilani and A. A. Ismaeel, MATEC Web of Conferences 131, 01004 UTP-UMP SES 2017.

12. H. H. Al-Kayiem, K. Y. Yin, and C.Y. Sing. Advanced Computational Methods and Experiments in Heat Transfer XII, WIT Transactions on Engineering Sciences 7, 61-72 (2012).

13. O. C. Aja, H. H. Al-Kayiem, and Z. A. Abdul Karim, National Postgraduate Conference (NPC), IEEE - Institute of Electrical and Electronics Engineers, 2011, pp. 1-6.

14. H. H. Al-Kayiem, A.O. Chikere, S. L. Lee, and K. Y. Yin, Patent Application No: PI 2011001224 (2011).

15. J. Li, H. Guo, Q. Cheng, and S. Huang, Energy Conversion and Management 133, 8796 (2017).

16. S.S. Al-Azawie, S. Hassan, and M. F. Zamri, WIT Transactions on Ecology and the Environment 186, (2014). 